\title{
Proliferative Vitreoretinopathy: A Review
}

\author{
Sana Idrees, $\mathbf{M D}^{1}$, Jayanth Sridhar, $\mathbf{M D}^{2}$, and Ajay E. Kuriyan, MD, MS ${ }^{1}$ \\ ${ }^{1}$ Flaum Eye Institute, University of Rochester Medical Center, Rochester, NY, USA \\ ${ }^{2}$ Bascom Palmer Eye Institute, University of Miami, Miami, FL, USA
}

\section{Abstract}

Proliferative vitreoretinopathy (PVR) is the most common cause for failure of rhegmatogenous retinal detachment repair and is characterized by the growth and contraction of cellular membranes within the vitreous cavity and on both sides of the retinal surface as well as intraretinal fibrosis. Currently, PVR is thought to be an abnormal wound healing response that is primarily driven by inflammatory, retinal, and RPE cells. At this time, surgery is the only management option for PVR as there is no proven pharmacologic agent for the treatment or prevention of PVR. Laboratory research to better understand PVR pathophysiology and clinical trials of various agents to prevent PVR formation are ongoing.

\section{Introduction}

Proliferative vitreoretinopathy (PVR) is the most common cause for failure of rhegmatogenous retinal detachment repair and is characterized by the growth and contraction of cellular membranes within the vitreous cavity and on both sides of the retinal surface as well as intraretinal fibrosis (Figure 1). ${ }^{1,2}$ Contraction of these membranes can cause the retina to redetach and transform a rhegmatogenous detachment into a tractional detachment. ${ }^{3}$ Intraretinal fibrosis can prevent the retina from flattening even after removal of all membranes. The incidence of PVR in all cases of retinal detachment is estimated to be 5$10 \% .^{4,5}$ The incidence of PVR has largely remained unchanged in prospective studies despite the evolution of vitreoretinal techniques over the past 25 years, including valved trocars and smaller gauge instumentation. ${ }^{6-9}$

Approximately $77 \%$ of postoperative forms of PVR appear within one month after retinal detachment surgery and $95 \%$ appear within 45 days. ${ }^{2,4}$ Following PVR detachment surgery, the anatomic success rate has been reported to be $45-85 \% .^{10-15}$ The final functional success rates of PVR detachment surgery were $26-67 \%$, with functional success defined by most studies as a final visual acuity of $5 / 200$ or better. ${ }^{10,16-18}$

Numerous risk factors for the development of PVR have been identified. Almost all risk factors for PVR are associated with intravitreal dispersion of retinal pigment epithelial cells or breakdown of the blood-ocular barrier, which are prerequisite to the development of PVR.

Correspondence: Ajay E. Kuriyan, MD, MS, 601 Elmwood Avenue, Box 659, Rochester, NY 14642, Phone: 585-276-5482, Fax: 585-276-0292, ajay_kuriyan@urmc.rochester.edu. 
${ }^{1}$ Preoperative risk factors include prolonged intraocular inflammation, prior infectious retinitis, lower intraocular pressure secondary to intraocular inflammation, vitreous hemorrhage, aphakia, prior intraocular surgery, choroidal detachment, retinal breaks greater than one clock hour, larger number of breaks, larger extent of retinal detachment, and preoperative grade A or B PVR. ${ }^{4,19-26}$ Intraoperative risk factors for PVR development include vitreous or subretinal hemorrhage, inability to completely seal a retinal tear, intraoperative choroidal detachment, pigment release during endodrainage, excessive cryotherapy and endolaser, and vitreous loss during external subretinal fluid drainage. 4,24,26-29 Postoperative risk factors for inducing PVR formation include prolonged inflammation or uveitis, intraocular hemorrhage after surgery, choroidal detachment, use of air or sulfur hexafluoride $\left(\mathrm{SF}_{6}\right)$ or air, multiple surgical procedures, and persistent traction on retinal breaks. ${ }^{1,2,19,26,27,30}$ The only identified modifiable risk factor associated with PVR is cigarette smoking. ${ }^{31}$

\section{Proliferative Vitreoretinopathy Grading}

The first widely recognized classification system for PVR was published by The Retina Society Terminology Committee in 1983 (Table 1). Grade A PVR was defined as the presence of vitreous haze and pigment clumps. ${ }^{3}$ Grade B PVR included the presence of surface retinal wrinkling and/or rolled edges of the retinal break with possible retinal stiffness and vessel tortuosity. ${ }^{3}$ Grade C PVR was defined as the presence of full thickness retinal folds in one (C-1), two (C-2), or three (C-3) quadrants. ${ }^{3}$ Grade D was defined as fixed retinal folds in four quadrants resulting in a wide funnel shape (D-1), narrow funnel shape (D-2), or closed funnel without a view of the optic disc (D-3). ${ }^{3}$

One of the major shortcomings of this classification scheme is the lack of differentiation between anterior and posterior PVR. In order to address this, the Silicone Study recommended a new classification scheme (Table 1): Grades A and B remained the same, but Grades $\mathrm{C}$ and D were replaced with Grades $\mathrm{P}$ (posterior form) and A (anterior form). ${ }^{32}$ Grades $\mathrm{P}$ and $\mathrm{A}$ were further defined by the types of contraction and the extent of PVR was measured by the number of clock hours involved. ${ }^{32}$

The Retina Society Terminology Committee updated its classification scheme in 1991 (Table 1). ${ }^{33}$ The new scheme describes three grades of increasing severity and emphasized the anterior and posterior locations of proliferation. Grades A and B remained the same. Grade $\mathrm{C}$ was modified to include a more detailed description of the location of proliferation, types of contraction, and extent in clock hours. Additionally, Grade D was eliminated. Grade C was defined as a full-thickness retinal folds and/or subretinal bands and pathologic changes that could be posterior, anterior, or both. Posterior grade C PVR was divided into focal contractions resulting in starfold membrane formation (Type 1) and/or diffuse contractions resulting from confluent starfolds that can result in a closed funnel configuration (Type 2). Grade C PVR included anterior or posterior subretinal bands (Type 3). Anterior grade $\mathrm{C}$ was divided into circumferential contraction (Type 4) along the posterior margin of the vitreous base and anterior displacement (Type 5) or the peripheral retina. ${ }^{33}$ However, due to the complexity of this grading scheme, it has rarely been incorporated into clinical practice. 
Additionally, each of the different grading schemes are used in clinical studies and approximately $25 \%$ of PVR studies do not use or identify a grading scheme. ${ }^{34}$

\section{Pathophysiology}

PVR is a multifactorial process that is a result of scarring, the end stage of wound healing, after retinal detachment (Figure 2). ${ }^{2}$ When a rhegmatogenous retinal detachment occurs, two primary events occur that act as the initiating factors of the potential PVR cascade. These events are the breakdown of the blood-retinal barriers and retinal hypoxia. ${ }^{1,4,35}$ The alteration of the interface between the outer retina and the retinal pigment epithelium (RPE) can result in the migration of the RPE cells into the vitreous cavity and onto the retina surface, and migration of retinal cells (e.g. glial cells) through the retina onto its surface.

When the blood-retinal barrier is disrupted, this leads to an increase in the chemotactic and mitogenic activity in the vitreous cavity. ${ }^{36}$ This occurs secondary to the influx of both cytokines and growth factors from the systemic circulation and influx of systemic circulation inflammatory cells that interact with hyalocytes, various retinal cells (e.g. glial cells), and retinal pigment epithelial (RPE) cells to drive further local production of cytokines and growth factors in the vitreous cavity.

Multiple inflammatory cells have been identified in the vitreous fluid and epiretinal membranes of PVR patients, including macrophages, CD4+ and CD8+ T lymphocytes, B lymphocytes, major histocompatibility (MHC) class II positive cells..$^{37,38,39-41}$ Deposits of immunoglobulins and complement have also been found in PVR epiretinal membranes and vitreous fluid. ${ }^{37,42}$ Intracellular adhesion molecule 1 (ICAM-1) and lymphocyte functionassociated antigen 1 (LFA-1), which mediate the interaction of leukocytes with other cells and the extracellular matrices, have also been found in PVR membranes. ${ }^{43}$

Growth factors and cytokines/chemokines enter the vitreous cavity through the impaired blood retina barrier and through interaction between the immune cells and local cells of the retina and vitreous. Some of the most important among them are platelet-derived growth factor (PDGF), hepatocyte growth factor (HGF), vascular endothelial growth factor (VEGF), epidermal growth factor (EGF), granulocyte-colony stimulating factor (G-CSF), acidic and basic fibroblastic growth factor (aFGF and bFGF), insulin-like growth factor 1 (IGF-1), connective tissue growth factor (CTGF), transforming growth factor a (TGF-a), transforming growth factor $\beta$ (TGF- $\beta$ ), tumor necrosis factor $a$ (TNF- $a$ ), interferon $\beta$ (IFN- $\beta$ ), interferon $\gamma$ (INF $\gamma$ ), interleukin 1 (IL-1), interleukin $1 \beta$ (IL-1 $\beta$ ), interleukin 6 (IL-6), interleukin 8 (IL-8), interleukin 10 (IL-10), and chemokines such as C-C motif chemokine ligand 3, 4, and 5 (CCL3, CCL4, and CCL5). ${ }^{44-55}$ Several of these growth factors and cytokines have been implicated in the stimulation of RPE and glial cells. ${ }^{56-58,44}$ The presence and concentration of growth factors, cytokines, and chemokines may be biomarkers for predicting development and severity of PVR. ${ }^{45,59-61}$

TGF- $\beta$ is a cytokine that regulates the differentiation, migration, apoptosis, and immune function of cells as well as the synthesis of the extracellular matrix. It has been found in high concentrations in the vitreous of patients with PVR. ${ }^{62}$ Quantities of TGF- $\beta 2$ were found to be directly proportional to the extent of fibrosis. ${ }^{63} \mathrm{PDGF}$ is a growth factor that functions in 
intercellular interaction between retinal cells. ${ }^{64}$ Studies have shown that PDGF receptor a (PDGFR-a) is activated in higher proportion in eyes with PVR. Direct activation of PDGFR- $a$ by PDGF leads to rapid clearance of the receptor from the cell surface with subsequent degradation. Non-PDGFs, such as VEGF, bFGF, EGF, insulin, and HGF, can also function to indirectly activate the PDGFR-a receptor by inducing tyrosine phosphorylation of PDGFR- $a$. Indirect activation of the PDGFR- $a$ by non-PDGFs promotes persistent receptor signaling and induces prolonged activation of phosphatidylinositol 3kinase (PI3K)/Akt, activating murine double minute (MRM2) to suppress p53 levels, and drive processes involved in PVR-survival, proliferation, and contraction. ${ }^{65,66}$

Many studies of epiretinal membranes in PVR have identified fibroblast or fibrocyte cells. ${ }^{67}$ Some have argued that these cells represent transformed RPE cells or originate from vascular endothelial cells, glial cells, macrophages, or hyalocytes. ${ }^{38,68-70}$ Based upon the finding of fibroblastic cells with cytoplasmic monofilaments, it has been proposed that membrane shortening is mediated by the intrinsic contraction of these cells, leading to the tractional forces responsible for the clinical features of PVR. Another study suggested an alternate mechanism of membrane contraction in which collagen fibers are pulled by the RPE cells, alternating the extension and retraction of their lamellipodia. ${ }^{70}$ Through either mechanism, the contraction can result in additional retinal breaks and redetachment of the retina. $^{4}$

After separation of the retina in a retinal detachment, the retinal outer layers become ischemic and the photoreceptors undergo cell death. ${ }^{71}$ While there are several pathways for cell death, apoptosis is the principal mechanism of photoreceptor loss after a retinal detachment. ${ }^{72,73}$ Apoptosis has two major signaling cascades, the extrinsic and intrinsic pathways, which lead to DNA fragmentation and cell death. Both pathways involve caspases. ${ }^{74-76}$ The initiation of photoreceptor apoptosis involves the release of cytokines from stressed and damaged tissues. The cytokines have chemotactic properties, which can attract and activate macrophages, Mueller cells, astrocytes, and microglia. ${ }^{51,54,59,77-82}$ The activation of these cells lead to oxidative stress that could contribute to further cytotoxic effect on the photoreceptors after a retinal detachment. ${ }^{77}$ Additionally, retinal detachment was found to induce the proliferation of non-neuronal cells, such as astrocytes, endothelial cells, pericytes, and microglia, peaking at $3-4$ days after retinal detachment. ${ }^{83}$ Reattachment of the retina can reverse some of these changes, including proliferation of endothelial cells and pericytes, especially if performed within one day. ${ }^{84}$ Cell death pathways may influence the development of intraretinal fibrosis in PVR.

The role of genetics in PVR development has been studied by the Retina 4 Project using a candidate gene association study. Two pro-fibrotic genes, SMAD7 and the TNF locus and two genes involved in apoptosis, p53 and MDM2, have been implicated in the formation of PVR through this study. The identification of both fibrotic and apoptotic genes further supports the theory that both of these pathologic processes play a key role in the development of PVR. 


\section{Pharmacologic prevention and treatment of PVR}

At this time there is no proven pharmacologic agent for the treatment or prevention of PVR. Pharmacologic interventions have mostly targeted inflammation, cell proliferation, and fibrosis. ${ }^{2}$ Corticosteroids were the first drugs tested for PVR. Experimental animal models showed some efficacy with intravitreal triamcinolone acetonide or topical and systemic corticosteroids, but clinical trials in patients showed a poor response. ${ }^{85-87}$ A prospective, randomized controlled study of intravitreal triamcinolone acetonide injection at the time of pars plana vitrectomy with $\mathrm{SiO}$ tamponade in grade C PVR showed no improvement in anatomic success, visual acuity, or PVR development. ${ }^{88}$ Triamcinolone acetonide is sometimes employed in retinal detachment repair for vitreous staining, but a large prospective multicenter study showed no difference in outcomes between patient undergoing vitrectomy with triamcinolone assisted staining and those without. ${ }^{89}$ Additionally, the use of heparin with dexamethasone in the vitrectomy-infusion fluid during vitrectomy for PVR increased the rate of postoperative hemorrhage, but this did not impact visual outcomes. ${ }^{90} \mathrm{~A}$ recent prospective clinical trial investigating the efficacy of slow-release $0.7 \mathrm{mg}$ dexamethasone intravitreal implant (Ozurdex, Allergan Inc, Irvine, CA) as an adjunct for PVR grade $\mathrm{C}$ treatment found no difference in the anatomic or functional success compared to vitrectomy with $\mathrm{SiO}$ placement without the dexamethasone implant. ${ }^{46}$

Anti-proliferative and anti-neoplastic agents studied for PVR prevention or treatment included compounds such as 5-fluorouracil (5-FU), daunorubicin, taxol, colchicine, retinoic acid, ribozymes, vincristine, cisplatin, adriamycin, mitomycin, and dactomycin. 5-FU is an antimetabolite that inhibits synthesis and fibroblast proliferation and has been one of the most tested compounds for treatment of PVR. 5-FU showed beneficial results in animal models, but had poor results with significant side effects in humans. ${ }^{85,86} \mathrm{~A}$ combination therapy of steroids or 5-FU with low molecular weight heparin (LMWH), an anticoagulant that binds many growth factors, was also studied in a large, randomized, controlled trial, which did not reveal any improvement in anatomical or visual outcomes in macularinvolving PVR detachments and resulted in worse visual outcomes for patients with macula sparing PVR retinal detachments. ${ }^{91}$

The Daunorubicin Study Group investigated the safety and efficacy of daunorubicin, an anthracycline antibiotic that arrests cell proliferation and cell migration, during vitrectomy in eyes with PVR. They found that daunorubicin use resulted in a small reduction in the reoperation rate in PVR patients undergoing retinal surgery. There was no difference in visual acuity and reattachment rate at one year. ${ }^{92}$ DNA-RNA chimeric ribozymes that target proliferating cell nuclear antigen (PCNA) showed promise in pre-clinical studies, but failed to demonstrate anatomical or visual benefits in multicenter clinical trials for PVR. ${ }^{93,94}$

Anti-VEGF agents have been shown to be effective at inhibiting experimental models of PVR through inhibition of indirect PDGFR activation. ${ }^{95}$ A prospective trial of patients with PVR grade $\mathrm{C}$ undergoing vitrectomy with silicone oil ( $\mathrm{SiO}$ ) placement randomized patients to receive intravitreal bevacizumab $1.25 \mathrm{mg}$ at the conclusion of the case, and the results showed no difference in visual acuity, redetachment rate, and PVR recurrence between the groups receiving and not receiving bevacizumab at 7 months. ${ }^{96}$ Similar results were observed in a patients with PVR grade B or better. ${ }^{97}$ 
Retinoic acid promotes growth arrest of RPE cells in vitro. A small $(\mathrm{n}=35)$ prospective randomized clinical trial of oral retinoic acid use in patients with PVR grade $\mathrm{C}$ undergoing vitrectomy, demonstrated significantly lower the rates retinal re-detachment and macular pucker formation and improved vision in patients being treated with oral retinoic acid. ${ }^{98} \mathrm{~A}$ larger prospective randomized controlled trial has been conducted and the results are forthcoming.

Methotrexate has been found to inhibit an in vitro model of PVR by inhibiting cell proliferation and inducing regulated cell death. ${ }^{99}$ One retrospective study evaluating patients with severe recurrent PVR and tractional retinal detachment or severe intraocular inflammation at high risk for PVR found that these patients had a lower incidence of PVR when treated with intravitreal methotrexate infusion during vitrectomy. ${ }^{100}$ Methotrexate has been shown to be safe and well tolerated in silicone-filled eyes ${ }^{101}$ and is currently being studied using serial injections in post-operative PVR eyes with silicone-oil.

Several additional agents have been found to be effective at preventing or treating in vitro and in vivo models of PVR. Taxol and colchicine are agents that function to stabilize and inhibit microtubule formation, which could reduce migration and proliferation of cells. These agents were found to be successful in pre-clinical models of PVR. ${ }^{102}$ Glucosamine is an inhibitor of N-linked oligosaccharide biosynthesis and processing, which suppresses RPE cell proliferation in vitro and interferes with the TGF- $\beta$ signaling pathway in RPE cells. ${ }^{103}$ Kinase inhibitors, such as hypericin or herbimycin, have shown positive results in preclinical PVR studies. ${ }^{104,105}$ Alkylphosphocholine is an inhibitor of protein kinase $\mathrm{C}$ shown to be effective against RPE cell attachment, migration, and proliferation in vitro. ${ }^{106}$ AG1295, an inhibitor of PDGFR kinase, significantly attenuated the development of retinal detachment without histologic or functional damage to the retina. ${ }^{107} \mathrm{~N}$-acetylcysteine (NAC) is an antioxidant that showed efficacy in rabbits by blocking activation of the PDGFR- $a$ and protecting rabbits from developing retinal detachment ${ }^{108}$ Epigallocatechin gallate, resveratrol, and curcumin are three polyphenolic agents that were tested in vitro with regards to their effect on proliferation of human RPE cells. Resveratrol was found to be the most potent. ${ }^{109}$ The inhibition of Rho-kinase has also been explored because of its effect of retinal cell survival and glial reactivity. In a retina culture, Rho-kinase inhibition had neuroprotective effects by attenuating the glial cell reactivity. ${ }^{110}$ Palomid 529 (Paloma Pharmaceuticals, Jamaica Plain, MA) is an inhibitor of the Akt/mTOR pathways that regulates intracellular signaling involved in cell cycle control. Palomid 529 suppressed Muller cell proliferation, glial scar formation, and photoreceptor death in an experimental model of retinal detachment in rabbits. ${ }^{111}$ HC-HA/PTX3, a soluble matrix component of amniotic membrane has been found to inhibit RPE cell proliferation and epithelialmesenchymal transition in vitro. ${ }^{112}$ The use of caspase inhibition has been studied extensively in experimental models, but few clinical trials have been conducted. ${ }^{113}$

Despite positive results in pre-clinical models of many agents, most of these therapies have failed to show efficacy in large prospective human clinical trials. This may be due to inadequate PVR animal models, an incomplete understanding of the disease pathophysiology, and the heterogeneous nature of PVR, which may not entirely be appreciated with current grading schemes. ${ }^{85,86}$ 


\section{Surgical treatment of PVR}

Given the lack of pharmacologic options for PVR, the mainstay of treatment for retinal detachments with PVR is surgical intervention. The surgical goals of retinal detachment with PVR is to reattach the retina as with all retinal detachments, however, the presence of preand sub-retinal membranes and intraretinal fibrosis in more severe grades of PVR often require additional maneuvers to relieve traction in order to reattach the retina and prevent redetachment. $^{2}$ The ideal timing of surgery for PVR is controversial. Some propose that the presence of clinical signs of activity may be an indicator to delay surgical intervention by a few weeks because the controlled trauma induced by additional surgery could stimulate additional cellular proliferation. ${ }^{4,114}$ Epiretinal proliferation in PVR takes an average of 612 weeks to develop completely. Delaying surgery would allow greater ease with membrane peel and ensure a more complete removal of the membranes. ${ }^{114}$ The decision to delay surgery must be balanced with the macula status and implications on visual recovery potential with further delay.

20-, 23-, 25- and 27-gauge vitrectomy have been found to be safe and effective in managing retinal detachments with PVR. ${ }^{15-121}$ Smaller gauge, transconjunctival vitrectomy techniques have not been found to yield superior outcomes, but may result in reduced postoperative inflammation. ${ }^{115}$ Scleral buckling (SB) is a surgical method that involves placement of a silicone band encircling the eye, which helps to support retinal breaks, support the vitreous base, and decrease anterior-posterior traction. ${ }^{114,122}$ The anatomic success rate with primary SB surgery for severe PVR retinal detachments is $34-47 \% .{ }^{114}$ One study found that in cases at high risk for postoperative PVR, combined vitrectomy and SB was associated with higher anatomical success compared to vitrectomy alone. ${ }^{123}$

Complete removal of the vitreous, including close vitreous base shaving, with scleral depression, if necessary, is recommended. Staining with triamcinolone acetonide is recommended to ensure a posterior vitreous detachment has been completed and that there is no residual posterior hyaloid and to better visualize the peripheral vitreous.

All pre-retinal membranes should be removed at the time of surgery. ${ }^{114}$ Vital dyes such as MembraneBlue (DORC International, Zuidland, the Netherlands) can be used to help visualize the PVR pre-retinal membranes. Indocyanine green dye can also be used to stain the internal limiting membrane (ILM) around the pre-retinal membranes to facilitate removal of the ILM and the overlying pre-retinal PVR membranes. Posterior pole ILM peeling in the absence of posterior pole pre-retinal PVR has also been advocated. Studies have found that posterior pole ILM peeling reduces the recurrence of posterior epiretinal membrane formation and one study found it reduced the risk of re-detachment. ${ }^{124-127}$ Further study is needed to assess the benefit of posterior pole ILM peeling in cases without posterior pole PVR.

Subretinal bands have a variable effect on the ability of the retina to reattach. If the subretinal bands are preventing retinal reattachment, they can be removed through a small retinotomy over a non-visually significant portion of the band or from under the retina if a large retinectomy is being performed. Breaking the subretinal band without removal may be sufficient for reattachment. Anterior membranes along the ciliary body or lens complex may 
develop in some patients. These membranes can be removed with the depression under coaxial viewing or using endoscopic viewing. ${ }^{128}$ Lensectomy should be considered in phakic patients with anterior pathology that is difficult to address due to the lens.

Perfluoro-n-octane (PFO) is a helpful adjunct for retinal detachment with PVR cases. ${ }^{129}$ Prior to peeling, PFO can be used to stabilize the posterior pole. After peeling, PFO can be increased to observe if the peeling was adequate to flatten the retina. If the retina cannot be adequately mobilized or completely reattached after peeling of all the apparent membranes, it may be secondary to intraretinal fibrosis leading to contraction and foreshortening of the retina. The use of a retinotomy (relaxing incision) or retinectomy should be considered in such cases. Meticulous hemostasis at the edge of the retinectomy/retinotomy is recommended to decrease the chance of further inflammation from bleeding. Once the retinal traction has all been relieved, a fluid-air exchange followed by endolaser to the breaks and edges of the retinectomy/retinotomy is performed. ${ }^{130}$

The last step of repair is selection of the tamponade agent, which is essential to allow time for chorioretinal adhesions to form from the laser. ${ }^{114}$ In the United States the options for endotamponade include air, intraocular gas, such as sulfur hexachloride $\left(\mathrm{SF}_{6}\right)$ or perfluoropropane $\left(\mathrm{C}_{3} \mathrm{~F}_{8}\right)$, or $\mathrm{SiO} .{ }^{131}$ Outside of the United States, there are additional gas options and heavy silicone oil available. ${ }^{131,132}$

The Silicone Study was a multicenter randomized clinical trial that compared long-acting gas with $\mathrm{SiO}$ for the surgical management of PVR with vitrectomy. ${ }^{32}$ The Silicone Study examined vitrectomy for PVR with long-acting gas compared to $\mathrm{SiO}$ for intraocular tamponade with respect to visual acuity, retinal detachment recurrence rate, and incidence of complications. It showed that $\mathrm{SiO}$ and $\mathrm{C}_{3} \mathrm{~F}_{8}$ were equivalent with respect to management of retinal detachments with PVR and had similar rates of success with respect to anatomical and visual outcomes. Additionally, the study showed that $\mathrm{SiO}$ and $\mathrm{C}_{3} \mathrm{~F}_{8}$ were superior to $\mathrm{SF}_{6}$ in terms of visual outcomes. ${ }^{133}$ The selection of tamponade agent must be individualized to the patient, including consideration of air travel needs and ability to return to the operating room.

\section{Visual and anatomic outcomes in PVR}

Despite repeated interventions, $10-40 \%$ of retinal detachments with PVR cases remain attached despite repeated surgery attempts. ${ }^{4,85}$ In one study of complicated retinal detachments mostly involving proliferative vitreoretinopathy, only 39\% remained attached long term after a mean follow up period of 30 months when vitrectomy with heavy silicone oil ( $\mathrm{SiO})$ tamponade was used. ${ }^{134}$ Furthermore, even with anatomic success, patients can have poor visual outcomes. ${ }^{6}$ Visual acuity of 5/200 or better was achieved in $40-80 \%$ of patients after repair of retinal detachments with PVR. ${ }^{4,85}$ The poor functional results have been attributed to possible changes in the macula, such as RPE irregularities, macular pucker, cystoid macular edema, and subretinal fibrosis. ${ }^{135}$ These changes could also be a result of macroscopic changes secondary to formation of epiretinal, intraretinal, or subretinal membranes. ${ }^{136}$ Anterior PVR and multiple surgeries for repair are associated with worse visual outcomes. ${ }^{2,122}$ In patients that demonstrate anatomic and functional success three 
years after their last surgery, there is a high likelihood that results will be maintained long term. ${ }^{133}$

\section{Future directions}

The use of adjunctive treatments to prevent cellular proliferation holds promise for the prevention of PVR or recurrence after surgery. ${ }^{6}$ Additional progress in developing grading schemes that are easy to use in clinical practice and account for the heterogeneity of PVR will be helpful in standardizing clinical PVR research. Several pre-surgical risk factors for PVR development have been identified. Further research into genetic, imaging, or biochemical biomarkers could potentially aid in the identification of the ideal patient population at risk for PVR for future clinical trials. ${ }^{45,137}$ While awaiting ongoing PVR clinical trial results for different agents, such as retinoic acid and methotrexate, additional pre-clinical research is continuing to identify other potential agents to ameliorate PVR formation. ${ }^{138}$ The role of cell death in PVR is continuing to be studied and is a novel potential therapeutic target. ${ }^{139-141}$ Further innovations in vitreoretinal surgery devices, viewing systems, and instrumentation may also help improve surgical PVR outcomes. Ideally, in the future, pharmaceutical and surgical interventions for PVR will yield better anatomic and visual outcomes.

\section{Acknowledgments}

Sources of funding: Unrestricted grant from Research to Prevent Blindness (Flaum Eye Institute, University of Rochester Medical Center) and NIH P30 EY001319

\section{References}

1. Nagasaki H, Shinagawa K, Mochizuki M. Risk factors for proliferative vitreoretinopathy. Prog Retin Eye Res. 1998;17(1):77-98. [PubMed: 9537796]

2. Pastor JC. Proliferative vitreoretinopathy: an overview. Surv Ophthalmol. 1998;43(1):3-18. [PubMed: 9716190]

3. The classification of retinal detachment with proliferative vitreoretinopathy. Ophthalmology. 1983;90(2):121-125. [PubMed: 6856248]

4. Pastor JC, de la Rúa ER, Martín F. Proliferative vitreoretinopathy: risk factors and pathobiology. Prog Retin Eye Res. 2002;21(1):127-144. [PubMed: 11906814]

5. Pennock S, Haddock LJ, Mukai S, Kazlauskas A. Vascular endothelial growth factor acts primarily via platelet-derived growth factor receptor a to promote proliferative vitreoretinopathy. Am J Pathol. 2014;184(11):3052-3068. doi:10.1016/j.ajpath.2014.07.026 [PubMed: 25261788]

6. Charteris DG, Sethi CS, Lewis GP, Fisher SK. Proliferative vitreoretinopathy-developments in adjunctive treatment and retinal pathology. Eye Lond Engl. 2002;16(4):369-374. doi:10.1038/ sj.eye.6700194

7. Leiderman YI, Miller JW. Proliferative vitreoretinopathy: pathobiology and therapeutic targets. Semin Ophthalmol. 2009;24(2):62-69. doi:10.1080/08820530902800082 [PubMed: 19373688]

8. Heimann H, Bartz-Schmidt KU, Bornfeld N, et al. Scleral buckling versus primary vitrectomy in rhegmatogenous retinal detachment: a prospective randomized multicenter clinical study. Ophthalmology. 2007;114(12):2142-2154. doi:10.1016/j.ophtha.2007.09.013 [PubMed: 18054633]

9. Oellers P, Stinnett S, Hahn P. Valved versus nonvalved cannula small-gauge pars plana vitrectomy for repair of retinal detachments with Grade $\mathrm{C}$ proliferative vitreoretinopathy. Clin Ophthalmol Auckl NZ. 2016;10:1001-1006. doi:10.2147/OPTH.S104901 
10. Grigoropoulos VG, Benson S, Bunce C, Charteris DG. Functional outcome and prognostic factors in 304 eyes managed by retinectomy. Graefes Arch Clin Exp Ophthalmol Albrecht Von Graefes Arch Klin Exp Ophthalmol. 2007;245(5):641-649. doi:10.1007/s00417-006-0479-z

11. Blumenkranz MS, Azen SP, Aaberg T, et al. Relaxing retinotomy with silicone oil or long-acting gas in eyes with severe proliferative vitreoretinopathy. Silicone Study Report 5. The Silicone Study Group. Am J Ophthalmol. 1993;116(5):557-564. [PubMed: 8238214]

12. Bovey EH, De Ancos E, Gonvers M. Retinotomies of 180 degrees or more. Retina Phila Pa. 1995;15(5):394-398.

13. Federman JL, Eagle RC. Extensive peripheral retinectomy combined with posterior 360 degrees retinotomy for retinal reattachment in advanced proliferative vitreoretinopathy cases. Ophthalmology. 1990;97(10):1305-1320. [PubMed: 2243681]

14. Haut J, Larricart P, van Effenterre G. Localized retinectomy indications in the treatment and prevention of retinal detachment. Ophthalmol J Int Ophtalmol Int J Ophthalmol Z Augenheilkd. 1984;188(4):212-215. doi:10.1159/000309365

15. Han DP, Lewis MT, Kuhn EM, et al. Relaxing retinotomies and retinectomies. Surgical results and predictors of visual outcome. Arch Ophthalmol Chic Ill 1960. 1990;108(5):694-697.

16. Tseng JJ, Barile GR, Schiff WM, Akar Y, Vidne-Hay O, Chang S. Influence of relaxing retinotomy on surgical outcomes in proliferative vitreoretinopathy. Am J Ophthalmol. 2005;140(4):628-636. doi:10.1016/j.ajo.2005.04.021 [PubMed: 16226515]

17. Quiram PA, Gonzales CR, Hu W, et al. Outcomes of Vitrectomy with Inferior Retinectomy in Patients with Recurrent Rhegmatogenous Retinal Detachments and Proliferative Vitreoretinopathy. Ophthalmology. 2006;113(11):2041-2047. doi:10.1016/j.ophtha.2006.05.039 [PubMed: 16952397]

18. de Silva DJ, Kwan A, Bunce C, Bainbridge J. Predicting visual outcome following retinectomy for retinal detachment. Br J Ophthalmol. 2008;92(7):954-958. doi:10.1136/bjo.2007.131540 [PubMed: 18556423]

19. Girard P, Mimoun G, Karpouzas I, Montefiore G. Clinical risk factors for proliferative vitreoretinopathy after retinal detachment surgery. Retina Phila Pa. 1994;14(5):417-424.

20. Rodriguez de la Rúa E, Pastor JC, Aragón J, et al. Interaction between surgical procedure for repairing retinal detachment and clinical risk factors for proliferative vitreoretinopathy. Curr Eye Res. 2005;30(2):147-153. doi:10.1080/02713680490904142 [PubMed: 15814473]

21. Rodríguez de la Rúz Franch E, Aragón Roca JA, Pastor Jimeno JC, et al. [Potential to predict the risk of developing proliferative vitreoretinopathy with the analysis of clinical factors of regmatogenous retinal detachments]. Arch Soc Espanola Oftalmol. 2000;75(12):807-812.

22. Wickham L, Bunce C, Wong D, Charteris DG. Retinal detachment repair by vitrectomy: simplified formulae to estimate the risk of failure. Br J Ophthalmol. 2011;95(9):1239-1244. doi:10.1136/bjo. 2010.190314 [PubMed: 21325394]

23. Yoshino Y, Ideta H, Nagasaki H, Uemura A. Comparative study of clinical factors predisposing patients to proliferative vitreoretinopathy. Retina Phila Pa. 1989;9(2):97-100.

24. Asaria $\mathrm{RH}$, Kon $\mathrm{CH}$, Bunce $\mathrm{C}$, et al. How to predict proliferative vitreoretinopathy: a prospective study. Ophthalmology. 2001;108(7):1184-1186. [PubMed: 11425672]

25. Bonnet M Clinical factors predisposing to massive proliferative vitreoretinopathy in rhegmatogenous retinal detachment. Ophthalmol J Int Ophtalmol Int J Ophthalmol Z Augenheilkd. 1984;188(3):148-152. doi:10.1159/000309357

26. Bonnet $\mathrm{M}$ The development of severe proliferative vitreoretinopathy after retinal detachment surgery. Grade B: a determining risk factor. Graefes Arch Clin Exp Ophthalmol Albrecht Von Graefes Arch Klin Exp Ophthalmol. 1988;226(3):201-205.

27. Cowley M, Conway BP, Campochiaro PA, Kaiser D, Gaskin H. Clinical risk factors for proliferative vitreoretinopathy. Arch Ophthalmol Chic Ill 1960. 1989;107(8):1147-1151.

28. Lleó Pérez A null, Campos Fernández R null, López Santoveña F null, Sánchez Lorente G null, Hernández Martínez FJ null, Navarro Palop C null. [Clinical risk factors for proliferative vitreoretinopathy after retinal detachment surgery]. Arch Soc Espanola Oftalmol. 2000;75(11): 741-750. 
29. Duquesne N, Bonnet M, Adeleine P. Preoperative vitreous hemorrhage associated with rhegmatogenous retinal detachment: a risk factor for postoperative proliferative vitreoretinopathy? Graefes Arch Clin Exp Ophthalmol Albrecht Von Graefes Arch Klin Exp Ophthalmol. 1996;234(11):677-682.

30. Grizzard WS, Hilton GF, Hammer ME, Taren D. A multivariate analysis of anatomic success of retinal detachments treated with scleral buckling. Graefes Arch Clin Exp Ophthalmol Albrecht Von Graefes Arch Klin Exp Ophthalmol. 1994;232(1):1-7.

31. Eliott D, Stryjewski TP, Andreoli MT, Andreoli CM. SMOKING IS A RISK FACTOR FOR PROLIFERATIVE VITREORETINOPATHY AFTER TRAUMATIC RETINAL DETACHMENT. Retina Phila Pa. 2017;37(7):1229-1235. doi:10.1097/IAE.0000000000001361

32. Lean JS, Stern WH, Irvine AR, Azen SP. Classification of proliferative vitreoretinopathy used in the silicone study. The Silicone Study Group. Ophthalmology. 1989;96(6):765-771. [PubMed: 2662099]

33. Machemer R, Aaberg TM, Freeman HM, Irvine AR, Lean JS, Michels RM. An updated classification of retinal detachment with proliferative vitreoretinopathy. Am J Ophthalmol. 1991;112(2):159-165. [PubMed: 1867299]

34. Di Lauro S, Kadhim MR, Charteris DG, Pastor JC. Classifications for Proliferative Vitreoretinopathy (PVR): An Analysis of Their Use in Publications over the Last 15 Years. J Ophthalmol. 2016;2016:7807596. doi:10.1155/2016/7807596 [PubMed: 27429798]

35. Friedlander M Fibrosis and diseases of the eye. J Clin Invest. 2007;117(3):576-586. doi:10.1172/ JCI31030 [PubMed: 17332885]

36. Campochiaro PA. Pathogenic mechanisms in proliferative vitreoretinopathy. Arch Ophthalmol Chic Ill 1960. 1997;115(2):237-241.

37. Baudouin C, Fredj-Reygrobellet D, Gordon WC, et al. Immunohistologic study of epiretinal membranes in proliferative vitreoretinopathy. Am J Ophthalmol. 1990;110(6):593-598. [PubMed: 1701071]

38. Esser P, Heimann K, Wiedemann P. Macrophages in proliferative vitreoretinopathy and proliferative diabetic retinopathy: differentiation of subpopulations. Br J Ophthalmol. 1993;77(11): 731-733. [PubMed: 8280690]

39. Charteris DG, Hiscott P, Grierson I, Lightman SL. Proliferative vitreoretinopathy. Lymphocytes in epiretinal membranes. Ophthalmology. 1992;99(9):1364-1367. [PubMed: 1407970]

40. Charteris DG. Proliferative vitreoretinopathy: pathobiology, surgical management, and adjunctive treatment. Br J Ophthalmol. 1995;79(10):953-960. [PubMed: 7488586]

41. Elner SG, Elner VM, Jaffe GJ, Stuart A, Kunkel SL, Strieter RM. Cytokines in proliferative diabetic retinopathy and proliferative vitreoretinopathy. Curr Eye Res. 1995;14(11):1045-1053. [PubMed: 8585935]

42. Grisanti S, Wiedemann P, Heimann K. [Proliferative vitreoretinopathy. On the significance of protein transfer through the blood-retina barrier]. Ophthalmol Z Dtsch Ophthalmol Ges. 1993;90(5):468-471.

43. Van Zee KJ, Kohno T, Fischer E, Rock CS, Moldawer LL, Lowry SF. Tumor necrosis factor soluble receptors circulate during experimental and clinical inflammation and can protect against excessive tumor necrosis factor alpha in vitro and in vivo. Proc Natl Acad Sci U S A. 1992;89(11): 4845-4849. [PubMed: 1317575]

44. Lei H, Velez G, Hovland P, Hirose T, Gilbertson D, Kazlauskas A. Growth factors outside the PDGF family drive experimental PVR. Invest Ophthalmol Vis Sci. 2009;50(7):3394-3403. doi: 10.1167/iovs.08-3042 [PubMed: 19324843]

45. Ricker LJAG, Kessels AGH, de Jager W, Hendrikse F, Kijlstra A, la Heij EC. Prediction of proliferative vitreoretinopathy after retinal detachment surgery: potential of biomarker profiling. Am J Ophthalmol. 2012;154(2):347-354.e2. doi:10.1016/j.ajo.2012.02.004 [PubMed: 22541653]

46. Banerjee PJ, Quartilho A, Bunce C, et al. Slow-Release Dexamethasone in Proliferative Vitreoretinopathy: A Prospective, Randomized Controlled Clinical Trial. Ophthalmology. 2017;124(6):757-767. doi:10.1016/j.ophtha.2017.01.021 [PubMed: 28237428] 
47. Andrews A, Balciunaite E, Leong FL, et al. Platelet-derived growth factor plays a key role in proliferative vitreoretinopathy. Invest Ophthalmol Vis Sci. 1999;40(11):2683-2689. [PubMed: 10509666]

48. Cui JZ, Chiu A, Maberley D, Ma P, Samad A, Matsubara JA. Stage specificity of novel growth factor expression during development of proliferative vitreoretinopathy. Eye Lond Engl. 2007;21(2):200-208. doi:10.1038/sj.eye.6702169

49. Hinton DR, He S, Jin ML, Barron E, Ryan SJ. Novel growth factors involved in the pathogenesis of proliferative vitreoretinopathy. Eye Lond Engl. 2002;16(4):422-428. doi:10.1038/sj.eye. 6700190

50. Dieudonné SC, La Heij EC, Diederen RMH, et al. Balance of vascular endothelial growth factor and pigment epithelial growth factor prior to development of proliferative vitreoretinopathy. Ophthalmic Res. 2007;39(3):148-154. doi:10.1159/000103234 [PubMed: 17534114]

51. Limb GA, Alam A, Earley O, Green W, Chignell AH, Dumonde DC. Distribution of cytokine proteins within epiretinal membranes in proliferative vitreoretinopathy. Curr Eye Res. 1994;13(11):791-798. [PubMed: 7851114]

52. Hui Y, Shi Y, Zhang X, Yang K, Yu C. [TNF-alpha, IL-8 and IL-6 in the early inflammatory stage of experimental PVR model induced by macrophages]. Zhonghua Yan Ke Za Zhi Chin J Ophthalmol. 1999;35(2):140-143.

53. Asaria RHY, Kon $\mathrm{CH}$, Bunce $\mathrm{C}$, et al. Silicone oil concentrates fibrogenic growth factors in the retro-oil fluid. Br J Ophthalmol. 2004;88(11):1439-1442. doi:10.1136/bjo.2003.040402 [PubMed: 15489490]

54. La Heij EC, van de Waarenburg MPH, Blaauwgeers HGT, et al. Basic fibroblast growth factor, glutamine synthetase, and interleukin-6 in vitreous fluid from eyes with retinal detachment complicated by proliferative vitreoretinopathy. Am J Ophthalmol. 2002;134(3):367-375. [PubMed: 12208248]

55. Mukherjee S, Guidry C. The insulin-like growth factor system modulates retinal pigment epithelial cell tractional force generation. Invest Ophthalmol Vis Sci. 2007;48(4):1892-1899. doi:10.1167/ iovs.06-1095 [PubMed: 17389525]

56. Flanders KC. Smad3 as a mediator of the fibrotic response. Int J Exp Pathol. 2004;85(2):47-64. doi:10.1111/j.0959-9673.2004.00377.x [PubMed: 15154911]

57. Saika S, Yamanaka O, Flanders KC, et al. Epithelial-mesenchymal transition as a therapeutic target for prevention of ocular tissue fibrosis. Endocr Metab Immune Disord Drug Targets. 2008;8(1): 69-76. [PubMed: 18393925]

58. Saika S, Yamanaka O, Nishikawa-Ishida I, et al. Effect of Smad7 gene overexpression on transforming growth factor beta-induced retinal pigment fibrosis in a proliferative vitreoretinopathy mouse model. Arch Ophthalmol Chic Ill 1960. 2007;125(5):647-654. doi: 10.1001/archopht.125.5.647

59. Kon CH, Occleston NL, Aylward GW, Khaw PT. Expression of vitreous cytokines in proliferative vitreoretinopathy: a prospective study. Invest Ophthalmol Vis Sci. 1999;40(3):705-712. [PubMed: 10067974]

60. Kon CH, Asaria RH, Occleston NL, Khaw PT, Aylward GW. Risk factors for proliferative vitreoretinopathy after primary vitrectomy: a prospective study. Br J Ophthalmol. 2000;84(5):506511. [PubMed: 10781515]

61. Rusnak S, Vrzalova J, Hecová L, Kozova M, Topolcan O, Ricarova R. Defining the seriousness of proliferative vitreoretinopathy by aspiration of cytokines from the anterior chamber. Biomark Med. 2013;7(5):759-767. doi:10.2217/bmm.13.65 [PubMed: 24044568]

62. Kawahara S, Hata Y, Kita T, et al. Potent inhibition of cicatricial contraction in proliferative vitreoretinal diseases by statins. Diabetes. 2008;57(10):2784-2793. doi:10.2337/db08-0302 [PubMed: 18599521]

63. Connor TB, Roberts AB, Sporn MB, et al. Correlation of fibrosis and transforming growth factorbeta type 2 levels in the eye. J Clin Invest. 1989;83(5):1661-1666. doi:10.1172/JCI114065 [PubMed: 2708527] 
64. Robbins SG, Mixon RN, Wilson DJ, et al. Platelet-derived growth factor ligands and receptors immunolocalized in proliferative retinal diseases. Invest Ophthalmol Vis Sci. 1994;35(10):3649_ 3663. [PubMed: 8088954]

65. Lei H, Rhéaume M-A, Velez G, Mukai S, Kazlauskas A. Expression of PDGFRa is a determinant of the PVR potential of ARPE19 cells. Invest Ophthalmol Vis Sci. 2011;52(9):5016-5021. doi: 10.1167/iovs.11-7442 [PubMed: 21642621]

66. Lei H, Velez G, Kazlauskas A. Pathological signaling via platelet-derived growth factor receptor \{alpha\} involves chronic activation of Akt and suppression of p53. Mol Cell Biol. 2011;31(9): 1788-1799. doi:10.1128/MCB.01321-10 [PubMed: 21357737]

67. Walshe R, Esser P, Wiedemann P, Heimann K. Proliferative retinal diseases: myofibroblasts cause chronic vitreoretinal traction. Br J Ophthalmol. 1992;76(9):550-552. [PubMed: 1420061]

68. Umazume K, Barak Y, McDonald K, Liu L, Kaplan HJ, Tamiya S. Proliferative vitreoretinopathy in the Swine-a new model. Invest Ophthalmol Vis Sci. 2012;53(8):4910-4916. doi:10.1167/iovs. 12-9768 [PubMed: 22729438]

69. Hui YN, Sorgente N, Ryan SJ. Posterior vitreous separation and retinal detachment induced by macrophages. Graefes Arch Clin Exp Ophthalmol Albrecht Von Graefes Arch Klin Exp Ophthalmol. 1987;225(4):279-284.

70. Glaser BM, Cardin A, Biscoe B. Proliferative vitreoretinopathy. The mechanism of development of vitreoretinal traction. Ophthalmology. 1987;94(4):327-332. [PubMed: 3587912]

71. Mitry D, Charteris DG, Fleck BW, Campbell H, Singh J. The epidemiology of rhegmatogenous retinal detachment: geographical variation and clinical associations. Br J Ophthalmol. 2010;94(6): 678-684. doi:10.1136/bjo.2009.157727 [PubMed: 19515646]

72. Chang CJ, Lai WW, Edward DP, Tso MO. Apoptotic photoreceptor cell death after traumatic retinal detachment in humans. Arch Ophthalmol Chic Ill 1960. 1995;113(7):880-886.

73. Cook B, Lewis GP, Fisher SK, Adler R. Apoptotic photoreceptor degeneration in experimental retinal detachment. Invest Ophthalmol Vis Sci. 1995;36(6):990-996. [PubMed: 7730033]

74. Lavrik IN, Golks A, Krammer PH. Caspases: pharmacological manipulation of cell death. J Clin Invest. 2005;115(10):2665-2672. doi:10.1172/JCI26252 [PubMed: 16200200]

75. Fuentes-Prior P, Salvesen GS. The protein structures that shape caspase activity, specificity, activation and inhibition. Biochem J. 2004;384(Pt 2):201-232. doi:10.1042/BJ20041142 [PubMed: 15450003]

76. Krammer PH, Arnold R, Lavrik IN. Life and death in peripheral T cells. Nat Rev Immunol. 2007;7(7):532-542. doi:10.1038/nri2115 [PubMed: 17589543]

77. Lo ACY, Woo TTY, Wong RLM, Wong D. Apoptosis and other cell death mechanisms after retinal detachment: implications for photoreceptor rescue. Ophthalmol J Int Ophtalmol Int J Ophthalmol Z Augenheilkd. 2011;226 Suppl 1:10-17. doi:10.1159/000328206

78. Capeans C, De Rojas MV, Lojo S, Salorio MS. C-C chemokines in the vitreous of patients with proliferative vitreoretinopathy and proliferative diabetic retinopathy. Retina Phila Pa. 1998;18(6): 546-550.

79. Cassidy L, Barry P, Shaw C, Duffy J, Kennedy S. Platelet derived growth factor and fibroblast growth factor basic levels in the vitreous of patients with vitreoretinal disorders. Br J Ophthalmol. 1998;82(2):181-185. [PubMed: 9613386]

80. El-Ghrably IA, Dua HS, Orr GM, Fischer D, Tighe PJ. Detection of cytokine mRNA production in infiltrating cells in proliferative vitreoretinopathy using reverse transcription polymerase chain reaction. Br J Ophthalmol. 1999;83(11):1296-1299. [PubMed: 10535861]

81. Mitamura Y, Takeuchi S, Yamamoto S, et al. Monocyte chemotactic protein-1 levels in the vitreous of patients with proliferative vitreoretinopathy. Jpn J Ophthalmol. 2002;46(2):218-221. [PubMed: 12062231]

82. Nakazawa T, Matsubara A, Noda K, et al. Characterization of cytokine responses to retinal detachment in rats. Mol Vis. 2006;12:867-878. [PubMed: 16917487]

83. Geller SF, Lewis GP, Anderson DH, Fisher SK. Use of the MIB-1 antibody for detecting proliferating cells in the retina. Invest Ophthalmol Vis Sci. 1995;36(3):737-744. [PubMed: 7890504] 
84. Lewis GP, Charteris DG, Sethi CS, Leitner WP, Linberg KA, Fisher SK. The ability of rapid retinal reattachment to stop or reverse the cellular and molecular events initiated by detachment. Invest Ophthalmol Vis Sci. 2002;43(7):2412-2420. [PubMed: 12091445]

85. Sadaka A, Giuliari GP. Proliferative vitreoretinopathy: current and emerging treatments. Clin Ophthalmol Auckl NZ. 2012;6:1325-1333. doi:10.2147/OPTH.S27896

86. Moysidis SN, Thanos A, Vavvas DG. Mechanisms of Inflammation in Proliferative Vitreoretinopathy: From Bench to Bedside. Mediators Inflamm. 2012;2012. doi: $10.1155 / 2012 / 815937$

87. Pastor JC, Rodríguez E, Marcos MA, Lopez MI. Combined pharmacologic therapy in a rabbit model of proliferative vitreoretinopathy (PVR). Ophthalmic Res. 2000;32(1):25-29. doi: 10.1159/000055583 [PubMed: 10657752]

88. Ahmadieh H, Feghhi M, Tabatabaei H, Shoeibi N, Ramezani A, Mohebbi MR. Triamcinolone acetonide in silicone-filled eyes as adjunctive treatment for proliferative vitreoretinopathy: a randomized clinical trial. Ophthalmology. 2008;115(11):1938-1943. doi:10.1016/j.ophtha. 2008.05.016 [PubMed: 18584876]

89. Yamakiri K, Sakamoto T, Noda Y, et al. One-year results of a multicenter controlled clinical trial of triamcinolone in pars plana vitrectomy. Graefes Arch Clin Exp Ophthalmol Albrecht Von Graefes Arch Klin Exp Ophthalmol. 2008;246(7):959-966. doi:10.1007/s00417-008-0829-0

90. Williams RG, Chang S, Comaratta MR, Simoni G. Does the presence of heparin and dexamethasone in the vitrectomy infusate reduce reproliferation in proliferative vitreoretinopathy? Graefes Arch Clin Exp Ophthalmol Albrecht Von Graefes Arch Klin Exp Ophthalmol. 1996;234(8):496-503.

91. Wickham L, Bunce C, Wong D, McGurn D, Charteris DG. Randomized controlled trial of combined 5-Fluorouracil and low-molecular-weight heparin in the management of unselected rhegmatogenous retinal detachments undergoing primary vitrectomy. Ophthalmology. 2007;114(4):698-704. doi:10.1016/j.ophtha.2006.08.042 [PubMed: 17398320]

92. Wiedemann P, Hilgers RD, Bauer P, Heimann K. Adjunctive daunorubicin in the treatment of proliferative vitreoretinopathy: results of a multicenter clinical trial. Daunomycin Study Group. Am J Ophthalmol. 1998;126(4):550-559. [PubMed: 9780100]

93. Mandava N, Blackburn P, Paul DB, et al. Ribozyme to proliferating cell nuclear antigen to treat proliferative vitreoretinopathy. Invest Ophthalmol Vis Sci. 2002;43(10):3338-3348. [PubMed: 12356843]

94. Schiff WM, Hwang JC, Ober MD, et al. Safety and efficacy assessment of chimeric ribozyme to proliferating cell nuclear antigen to prevent recurrence of proliferative vitreoretinopathy. Arch Ophthalmol Chic Ill 1960. 2007;125(9):1161-1167. doi:10.1001/archopht.125.9.1161

95. Pennock S, Kim D, Mukai S, et al. Ranibizumab is a potential prophylaxis for proliferative vitreoretinopathy, a nonangiogenic blinding disease. Am J Pathol. 2013;182(5):1659-1670. doi: 10.1016/j.ajpath.2013.01.052 [PubMed: 23582767]

96. Ghasemi Falavarjani K, Hashemi M, Modarres M, Hadavand Khani A. Intrasilicone oil injection of bevacizumab at the end of retinal reattachment surgery for severe proliferative vitreoretinopathy. Eye Lond Engl. 2014;28(5):576-580. doi:10.1038/eye.2014.21

97. Tousi A, Hasanpour H, Soheilian M. Intravitreal Injection of Bevacizumab in Primary Vitrectomy to Decrease the Rate of Retinal Redetachment: A Randomized Pilot Study. J Ophthalmic Vis Res. 2016;11(3):271-276. doi:10.4103/2008-322X.188390 [PubMed: 27621784]

98. Chang Y-C, Hu D-N, Wu W-C. Effect of oral 13-cis-retinoic acid treatment on postoperative clinical outcome of eyes with proliferative vitreoretinopathy. Am J Ophthalmol. 2008;146(3):440 446. doi:10.1016/j.ajo.2008.05.002 [PubMed: 18599016]

99. Amarnani D, Machuca-Parra AI, Wong LL, et al. Effect of Methotrexate on an In Vitro PatientDerived Model of Proliferative Vitreoretinopathy. Invest Ophthalmol Vis Sci. 2017;58(10):3940_ 3949. doi:10.1167/iovs.16-20912 [PubMed: 28777835]

100. Sadaka A, Sisk RA, Osher JM, Toygar O, Duncan MK, Riemann CD. Intravitreal methotrexate infusion for proliferative vitreoretinopathy. Clin Ophthalmol Auckl NZ. 2016;10:1811-1817. doi: 10.2147/OPTH.S111893 
101. Hardwig PW, Pulido JS, Bakri SJ. The safety of intraocular methotrexate in silicone-filled eyes. Retina Phila Pa. 2008;28(8):1082-1086. doi:10.1097/IAE.0b013e3181754231

102. Lemor M, de Bustros S, Glaser BM. Low-dose colchicine inhibits astrocyte, fibroblast, and retinal pigment epithelial cell migration and proliferation. Arch Ophthalmol Chic Ill 1960. 1986;104(8): $1223-1225$.

103. Liang C-M, Tai M-C, Chang Y-H, et al. Glucosamine inhibits epithelial-to-mesenchymal transition and migration of retinal pigment epithelium cells in culture and morphologic changes in a mouse model of proliferative vitreoretinopathy. Acta Ophthalmol (Copenh). 2011;89(6):e505-514. doi:10.1111/j.1755-3768.2011.02147.x

104. Machado RAF, Casella AMB, Malaguido MR, Oguido APMT. [Experimental study of vitreoretinal proliferation inhibition by the use of hypericin]. Arq Bras Oftalmol. 2009;72(5): 650-654. [PubMed: 20027403]

105. Imai K, Loewenstein A, Koroma B, Grebe R, de Juan E. Herbimycin A in the treatment of experimental proliferative vitreoretinopathy: toxicity and efficacy study. Graefes Arch Clin Exp Ophthalmol Albrecht Von Graefes Arch Klin Exp Ophthalmol. 2000;238(5):440-447.

106. Eibl KH, Lewis GP, Betts K, et al. The effect of alkylphosphocholines on intraretinal proliferation initiated by experimental retinal detachment. Invest Ophthalmol Vis Sci. 2007;48(3):1305-1311. doi:10.1167/iovs.06-0591 [PubMed: 17325177]

107. Zheng Y, Ikuno Y, Ohj M, et al. Platelet-derived growth factor receptor kinase inhibitor AG1295 and inhibition of experimental proliferative vitreoretinopathy. Jpn J Ophthalmol. 2003;47(2): 158-165. [PubMed: 12738549]

108. Lei H, Velez G, Cui J, et al. N-acetylcysteine suppresses retinal detachment in an experimental model of proliferative vitreoretinopathy. Am J Pathol. 2010;177(1):132-140. doi:10.2353/ajpath. 2010.090604 [PubMed: 20489144]

109. Alex AF, Spitznas M, Tittel AP, Kurts C, Eter N. Inhibitory effect of epigallocatechin gallate (EGCG), resveratrol, and curcumin on proliferation of human retinal pigment epithelial cells in vitro. Curr Eye Res. 2010;35(11):1021-1033. doi:10.3109/02713683.2010.506970 [PubMed: 20958191]

110. Tura A, Schuettauf F, Monnier PP, Bartz-Schmidt KU, Henke-Fahle S. Efficacy of Rho-kinase inhibition in promoting cell survival and reducing reactive gliosis in the rodent retina. Invest Ophthalmol Vis Sci. 2009;50(1):452-461. doi:10.1167/iovs.08-1973 [PubMed: 18757509]

111. Lewis GP, Chapin EA, Byun J, Luna G, Sherris D, Fisher SK. Muller cell reactivity and photoreceptor cell death are reduced after experimental retinal detachment using an inhibitor of the Akt/mTOR pathway. Invest Ophthalmol Vis Sci. 2009;50(9):4429-4435. doi:10.1167/iovs. 09-3445 [PubMed: 19369237]

112. He H, Kuriyan AE, Su C-W, et al. Inhibition of Proliferation and Epithelial Mesenchymal Transition in Retinal Pigment Epithelial Cells by Heavy Chain-Hyaluronan/Pentraxin 3. Sci Rep. 2017;7:43736. doi:10.1038/srep43736 [PubMed: 28252047]

113. Murakami Y, Miller JW, Vavvas DG. RIP kinase-mediated necrosis as an alternative mechanisms of photoreceptor death. Oncotarget. 2011;2(6):497-509. doi:10.18632/oncotarget.286 [PubMed: 21670490]

114. Coffee RE, Jiang L, Rahman SA. Proliferative vitreoretinopathy: advances in surgical management. Int Ophthalmol Clin. 2014;54(2):91-109. doi:10.1097/IIO.0000000000000023 [PubMed: 24613887]

115. Iwahashi-Shima C, Sato T, Bando H, Ikeda T, Emi K. Anatomic and functional outcomes of 25gauge vitrectomy for repair of eyes with rhegmatogenous retinal detachment complicated by proliferative vitreoretinopathy. Clin Ophthalmol Auckl NZ. 2013;7:2043-2049. doi:10.2147/ OPTH.S52260

116. Sato T, Emi K, Bando H, Ikeda T. Retrospective comparison of 25-gauge vitrectomy for repair of proliferative vitreoretinopathy with or without anterior proliferation. Graefes Arch Clin Exp Ophthalmol Albrecht Von Graefes Arch Klin Exp Ophthalmol. 2014;252(12):1895-1902. doi: $10.1007 / \mathrm{s} 00417-014-2846-5$ 
117. Sato T, Emi K, Bando H, Ikeda T. [Retrospective comparison of 25-gauge vitrectomy with 20gauge vitrectomy in the repair of retinal detachment complicated with proliferative vitreoretinopathy]. Nippon Ganka Gakkai Zasshi. 2012;116(2):100-107. [PubMed: 22509698]

118. Khan MA, Kuley A, Riemann CD, et al. Long-Term Visual Outcomes and Safety Profile of 27Gauge Pars Plana Vitrectomy for Posterior Segment Disease. Ophthalmology. 2018;125(3):423431. doi:10.1016/j.ophtha.2017.09.013 [PubMed: 29146307]

119. Erakgun T, Egrilmez S. Surgical outcomes of transconjunctival sutureless 23-gauge vitrectomy with silicone oil injection. Indian J Ophthalmol. 2009;57(2):105-109. [PubMed: 19237782]

120. Shah CP, Ho AC, Regillo CD, Fineman MS, Vander JF, Brown GC. Short-term outcomes of 25gauge vitrectomy with silicone oil for repair of complicated retinal detachment. Retina Phila Pa. 2008;28(5):723-728. doi:10.1097/IAE.0b013e318166976d

121. Riemann CD, Miller DM, Foster RE, Petersen MR. Outcomes of transconjunctival sutureless 25gauge vitrectomy with silicone oil infusion. Retina Phila Pa. 2007;27(3):296-303. doi: 10.1097/01.iae.0000242761.74813.20

122. Pennock S, Haddock LJ, Eliott D, Mukai S, Kazlauskas A. Is neutralizing vitreal growth factors a viable strategy to prevent proliferative vitreoretinopathy? Prog Retin Eye Res. 2014;40:16-34. doi:10.1016/j.preteyeres.2013.12.006 [PubMed: 24412519]

123. Storey P, Alshareef R, Khuthaila M, et al. Pars plana vitrectomy and scleral buckle versus pars plana vitrectomy alone for patients with rhegmatogenous retinal detachment at high risk for proliferative vitreoretinopathy. Retina Phila Pa. 2014;34(10):1945-1951. doi:10.1097/IAE. 0000000000000216

124. Minarcik JR, von Fricken MA. Virtual retinectomy: indocyanine green-assisted internal limiting membrane peeling as a surgical adjunct in repair of recurrent rhegmatogenous retinal detachment due to PVR. Clin Ophthalmol Auck1 NZ. 2012;6:631-636. doi:10.2147/OPTH.S29654

125. Rao RC, Blinder KJ, Smith BT, Shah GK. Internal limiting membrane peeling for primary rhegmatogenous retinal detachment repair. Ophthalmology. 2013;120(5):1102-1103.e1-2. doi: 10.1016/j.ophtha.2012.12.010 [PubMed: 23642744]

126. Akiyama K, Fujinami K, Watanabe K, Tsunoda K, Noda T. Internal Limiting Membrane Peeling to Prevent Post-vitrectomy Epiretinal Membrane Development in Retinal Detachment. Am J Ophthalmol. 2016;171:1-10. doi:10.1016/j.ajo.2016.08.015 [PubMed: 27544480]

127. Foveau P, Leroy B, Berrod J-P, Conart J-B. Internal Limiting Membrane Peeling in Macula-off Retinal Detachment Complicated by Grade B Proliferative Vitreoretinopathy. Am J Ophthalmol. 2018;191:1-6. doi:10.1016/j.ajo.2018.03.037 [PubMed: 29621507]

128. Boscher C, Kuhn F. An endoscopic overview of the anterior vitreous base in retinal detachment and anterior proliferative vitreoretinopathy. Acta Ophthalmol (Copenh). 2014;92(4):e298-304. doi:10.1111/aos.12303

129. Coll GE, Chang S, Sun J, Wieland MR, Berrocal MH. Perfluorocarbon liquid in the management of retinal detachment with proliferative vitreoretinopathy. Ophthalmology. 1995;102(4):630-638; discussion 638-639. [PubMed: 7724180]

130. Williamson TH, Gupta B. Planned delayed relaxing retinotomy for proliferative vitreoretinopathy. Ophthalmic Surg Lasers Imaging Off J Int Soc Imaging Eye. 2010;41(1):31-34. doi: 10.3928/15428877-20091230-06

131. Su X, Tan MJ, Li Z, et al. Recent Progress in Using Biomaterials as Vitreous Substitutes. Biomacromolecules. 2015;16(10):3093-3102. doi:10.1021/acs.biomac.5b01091 [PubMed: 26366887]

132. Williams RL, Kearns VR, Lo AC, et al. Novel heavy tamponade for vitreoretinal surgery. Invest Ophthalmol Vis Sci. 2013;54(12):7284-7292. doi:10.1167/iovs.13-11876 [PubMed: 24130181]

133. Abrams GW, Azen SP, McCuen BW, Flynn HW, Lai MY, Ryan SJ. Vitrectomy with silicone oil or long-acting gas in eyes with severe proliferative vitreoretinopathy: results of additional and long-term follow-up. Silicone Study report 11. Arch Ophthalmol Chic Ill 1960. 1997;115(3): 335-344.

134. Regler R, Sachs HG, Hillenkamp J, Helbig H, Framme C. Long-term evaluation of anatomic and functional results after complicated retinal detachment treated with pars plana vitrectomy and 
heavy silicone oil tamponade. Klin Monatsbl Augenheilkd. 2009;226(9):707-712. doi:10.1055/ s-0028-1109685 [PubMed: 19750420]

135. Kiss CG, Richter-Müksch S, Sacu S, Benesch T, Velikay-Parel M. Anatomy and function of the macula after surgery for retinal detachment complicated by proliferative vitreoretinopathy. Am J Ophthalmol. 2007;144(6):872-877. doi:10.1016/j.ajo.2007.08.001 [PubMed: 17937924]

136. Pastor JC, Méndez MC, de la Fuente MA, et al. Intraretinal immunohistochemistry findings in proliferative vitreoretinopathy with retinal shortening. Ophthalmic Res. 2006;38(4):193-200. doi: 10.1159/000093070 [PubMed: 16679807]

137. Rojas J, Fernandez I, Pastor JC, et al. Predicting proliferative vitreoretinopathy: temporal and external validation of models based on genetic and clinical variables. Br J Ophthalmol. 2015;99(1):41-48. doi:10.1136/bjophthalmol-2014-305263 [PubMed: 25075124]

138. Isotretinoin for Proliferative Vitreoretinopathy - Full Text View - ClinicalTrials.gov. https:// clinicaltrials.gov/ct2/show/NCT01445028. Accessed May 7, 2018.

139. Rojas J, Fernandez I, Pastor JC, et al. A genetic case-control study confirms the implication of SMAD7 and TNF locus in the development of proliferative vitreoretinopathy. Invest Ophthalmol Vis Sci. 2013;54(3):1665-1678. doi:10.1167/iovs.12-10931 [PubMed: 23258148]

140. Pastor-Idoate S, Rodríguez-Hernández I, Rojas J, et al. The T309G MDM2 gene polymorphism is a novel risk factor for proliferative vitreoretinopathy. PloS One. 2013;8(12):e82283. doi:10.1371/ journal.pone.0082283 [PubMed: 24349246]

141. Pastor-Idoate S, Rodriguez-Hernández I, Rojas J, et al. The p53 codon 72 polymorphism (rs 1042522) is associated with proliferative vitreoretinopathy: the Retina 4 Project. Ophthalmology. 2013;120(3):623-628. doi:10.1016/j.ophtha.2012.08.019 [PubMed: 23207172] 
Figure 1. Fundus photo of left eye with retinal detachment and proliferative vitreoretinopathy (PVR)

Fundus wide-field photograph of contracted cellular membranes associated with proliferative vitreoretinopathy leading to retinal redetachment in the setting of proliferative diabetic retinopathy. The patient was successfully reattached after membrane peel, relaxing retinectomy, and laser with silicone oil tamponade. 


\section{RETINAL DETACHMENT}

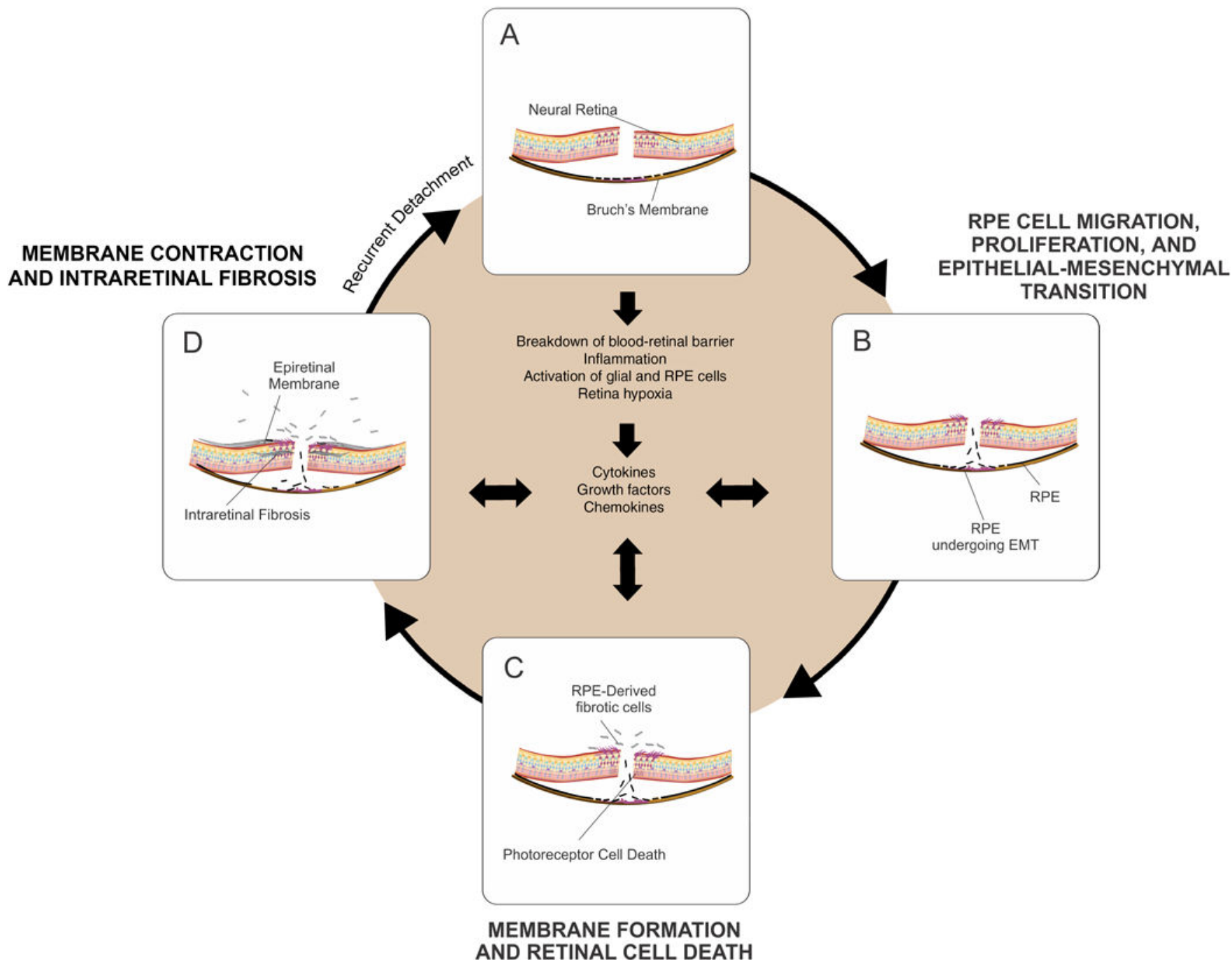

Figure 2. Pathophysiology of proliferative vitreoretinopathy

A retinal detachment sets off a cascade of events that can lead to proliferative vitreoretinopathy and subsequent redetachment of the retina. These events include breakdown of the blood-retinal barrier, inflammation, activation of glial and retinal pigment epithelium (RPE) cells, and retinal hypoxia. Subsequently, there is a release of cytokines, growth factors, and chemokines, which facilitate RPE cell migration, proliferation, and epithelial-mesenchymal transition. The RPE-derived fibrotic cells migrate into the vitreous and begin to lay down a membrane on the surface of the retina. The fibrotic membrane contracts and leads to recurrent detachment of the retina. Additionally, the outer retina becomes ischemic and retinal photoreceptors undergo cell death and intraretinal fibrosis occurs, leading to stiffening of the retina. 


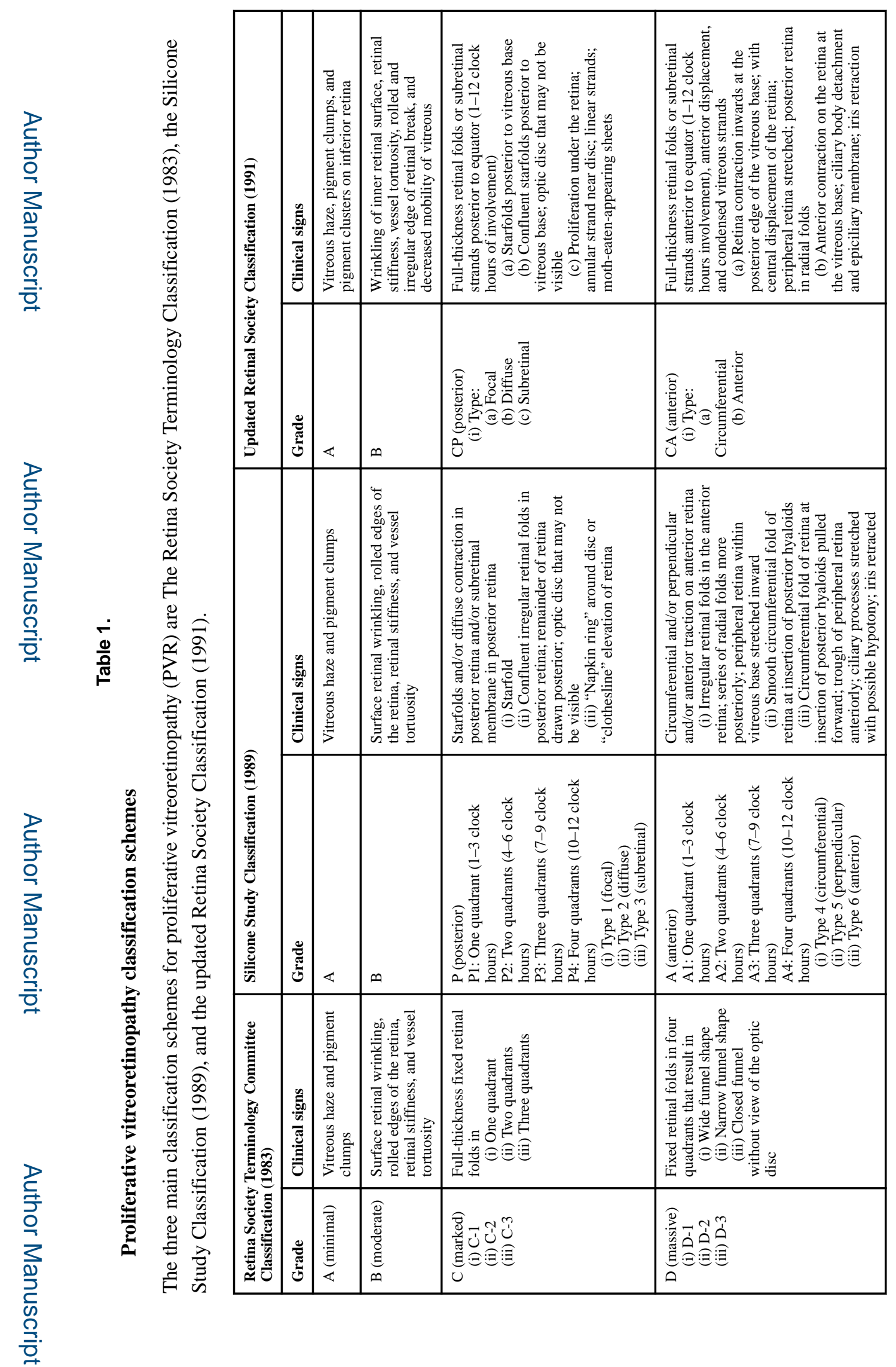

Int Ophthalmol Clin. Author manuscript; available in PMC 2020 January 01. 